\title{
El arte en el linde de lo humano
}

\section{The art on the edge of the human}

\author{
Maria Del Carmen Vaquero Cañestero \\ Facultad de Ciencias de la Educación. Universidad de Málaga. \\ cvaquero@uma.es
}

Recibido: 25 de enero de 2011

Aprobado: 3 de mayo de 2011

\section{Resumen}

El arte de las últimas décadas, reproductor y generador de un sistema cultural complejo y extremadamente dinámico, ha ampliado, en su labor visionaria, contestataria o comunicativa, la concepción más arraigada sometiendo a espectadoras y espectadores a la vivencia del arte desde parámetros ajenos o muy alejados de sus estructuras referenciales. Tanto es así que los esquemas personales, perpetuados tras una larga tradición predominantemente pictórica, han sido neutralizados y, aún más que eso, han sido invalidados.

El título de este artículo remite a Danto, A. (1999) y su "linde de la historia" pero lo hace desde el prisma del público que, desde hace décadas, asiste atónito a la deconstrucción de cada una de las premisas que fundamentan su idea de arte. En la discordancia entre la evolución vertiginosa de las manifestaciones artísticas de las últimas décadas, frente al estatismo que caracteriza a la figura del público, anclado a presupuestos caducos, reside uno de los fundamentos del proceso que conduce, día a día, a la deshumanización del arte.

Palabras Clave: Arte, espectador, obra de arte, experiencia artística.

Vaquero Casteñero, C. 2011: El arte en el linde de lo humano. Arte, Individuo y Sociedad, 23 (2),35-43

\begin{abstract}
Art from the last decades consider as a producer and generator of a complex cultural system and extremely dynamic, has expanded in a visionary way, argumentative and communicative, the most establish idea making people see art from another point of view, very far from their references. That is the reason why personal conceptions with a mainly pictorial tradition have been neutralized and even invalidated.

The title of this article refers to Danto, A. (1999) and his "Linde de la historia" but from public's point of view that since decades see astonished the deconstruction of all their fundamental art ideas. Within the references between the fast evolution of art expression in the latest times and the stationary concepts that remains in people, lives one of the main process that take them, day by day to the dehumanization of art.
\end{abstract}

Key Words: Art, viewer, artwork, artistic experience.

Vaquero Casteñero, C. 2011: The art on the edge of the human. Arte, Individuo y Sociedad, 23 (2), 35-43

Sumario: 1. Introducción, 2. Divergencias, 2.1 ¿Qué le exige el público al arte?, 2.2 Expectativas y obra de arte, 2.3 ¿Qué le exige el arte al público?, 2.4 El contexto del arte, 3. El artista, 4. Conclusiones. La deshumanización del arte. Referencias 


\section{Introducción}

La obra de arte es, más allá de sus innumerables definiciones, un ente sometido a perpetuo cambio, expuesto a un proceso de continua metamorfosis (Marchán, 2001). Ahí radica, precisamente, uno de sus valores esenciales: en su capacidad de materializar los ciclos e inquietudes implícitas a la sociedad y, a la vez, en mostrar a esta, en su reflejo, su ritmo más íntimo y vertiginoso.

En la sociedad actual, el valor de lo nuevo (Rosenberg, 1961, citado en Marchán 2001) se alza como uno de los factores determinantes en la configuración del ritmo colectivo. En el arte actual, como reflejo recíproco, es tal la primacía de lo nuevo, un arte "que teme sobre todo detenerse, antes humo que cristal" (Marina, 2006) que, ante la diversidad de sus manifestaciones, fundamentadas en muchas ocasiones en la revisión de períodos artísticos pasados, el espectador no encuentra acomodo. La fisicidad de la obra, tal como la entendía, se ha esfumado y, en su lugar, se exhiben, extraños artefactos que, en la misma medida en que se han liberado de cargas representativas o de formatos estáticos, son indicadores de un arte que camina hacia la deshumanización profetizada por Ortega y Gasset ya en 1925.

En La Deshumanización del Arte, este autor presiente la trascendencia del desencuentro actual entre obra y público en manifestaciones artísticas ajenas al complejo contexto de hoy. En realizaciones muy tempranas, desarrolladas bajo el impulso creador de las Primeras Vanguardias Artísticas del siglo XX, Ortega vislumbra ese valor futuro en lo que califica como "arte nuevo" (Ortega, 1987) y, dando un paso más, presagia la deshumanización en las realizaciones que florezcan a partir de este.

Anna María Guasch (2003), en un análisis de este distanciamiento desde un prisma mucho más cercano, manifiesta cómo "este público no reconoce como suyo el arte de su época, actitud de la que deriva el rechazo o cuando no una cierta acusación de ininteligibilidad, opacidad discursiva y dispersión". Este público, ante la falta de preparación, del conocimiento que presupone necesario para la experiencia artística, para la vivencia del arte, prefiere no exponerse y elude la confrontación.

\section{Divergencias}

\section{1. ¿Qué le exige el público al arte?}

Danto (1999), califica la mímesis como "el gran paradigma tradicional de las artes visuales (...) que sirvió admirablemente a los propósitos teoréticos del arte durante varios siglos". Si nos referimos al arte y su materialización, la obra de arte, en el contexto occidental, sería más adecuado albergar todas estas manifestaciones que preceden al arte moderno bajo la concepción de representación, en la que el carácter narrativo se erguía como referente absoluto. Sin embargo, la idea de mímesis es idónea para describir el tipo de relación que el espectador establece con la obra hasta la llegada del siglo XX. En la mímesis, en la supuesta voluntad del artista por reflejar todas y cada una de las cualidades de la realidad, reside el esfuerzo que el público considera indispensable para la categorización artística. Este tipo de creaciones, a su juicio, no exige un conocimiento que actúe como punto de partida.

A pesar de esto, el espectador, partiendo del presupuesto anterior, confuso y 
como mínimo cuestionable, hace algunas concesiones. En ocasiones permite que el artista transite por diferentes grados de iconicidad. De hecho, le perdona la evasión de la realidad y la desaparición de elementos reconocibles siempre y cuando sean sustituidos por otro tipo de recursos que también le resultan familiares (como el protagonismo del color en creaciones con altas dosis de expresividad), sin intuir la radical "emancipación de la naturaleza" (Kandinsky, 1997) que caracteriza al impulso artístico ya a comienzos del siglo pasado.

Si analizamos este hecho en un marco temporal amplio, podemos comprobar cómo en ocasiones la mímesis, que facilita la empatía del espectador con la obra en su intento por reconocer en ella parte de su realidad vivida, ha sido sustituida por otras formas de representación que ofrecen un tipo de nexos nuevos, tales como los llamados manierismos o periodos de transición en los que hay una tendencia hacia la "interpretación" de los referentes naturales y que suponen un paso previo a la liberación de la misión descriptiva del arte protagonizada por la irrupción de las Vanguardias.

En un recorrido por la sucesión de estilos artísticos, es fácil constatar cómo siempre ha habido estéticas con tendencia a suprimir lo anecdótico de lo real y a trascender lo percibido a través de la naturaleza (fuente de inspiración por excelencia), de forma que el grado de interpretación adquiriera protagonismo sobre cualquier descripción. El interés del arte de la pasada centuria reside en la completa reorganización de preceptos como: el triunfo de la forma (absolutamente autónoma), del objeto presentado (tras la simple elección), e incluso del concepto, obviando la acción interpretativa a la que el público estaba acostumbrado. En este sentido, desde principios de siglo, tomó especial relevancia el cómo decir las cosas, tanto es así que "el logro individual dependía de la innovación del lenguaje y de las formas de representación" (Harvey, 1998). Así, el arte comenzó a hablar exclusivamente de arte y lo hizo en ese contexto ideal de absoluta transformación del siglo XX.

Una de las consecuencias previsibles de este arte nuevo, carente de referencias, podía ser llegar a la plena comunicación, pues traía consigo una universalización del medio artístico. Sin embargo, la referencia a la realidad a través de vías alternativas y alejadas del virtuosismo anterior, hizo que se invalidaran, de un golpe, los recursos que ayudaban a conformar las estructuras referenciales del público.

\subsection{Expectativas y obras de arte}

El panorama artístico de las últimas décadas, gracias a la plataforma de transformación generada desde la Modernidad, ha evolucionado al ritmo vertiginoso que caracteriza al contexto actual. El arte, "resultante de la compleja interacción de los procesos de adaptación del individuo y la sociedad" (Read, 2000), ha trascendido sus propios parámetros en la medida en que ha cuestionado y cuestiona aspectos tan controvertidos como la propia integridad física de la obra.

Ajeno a esto el espectador, cuando asiste al espacio expositivo, anhela los productos acabados y la experiencia interpretativa a la que estaba relegado, sin embargo: 
Se enfrenta, por el contrario, con cosas que se tildan de obras de arte en montajes de textos escuetos y fotografías vulgares, en objetos industriales en los que no es posible detectar la mano del artista, en productos comerciales banales trasladados sin más desde el centro comercial a la galería, o en performances efimeras y transgresoras en las que se parodian deliberadamente los valores imperantes (Crow, 2001).

En este cruce de expectativas intervienen muchos factores, pero hay uno que resulta determinante. Desde el momento en que comienza a perder relevancia el objeto artístico como producto creado en su totalidad por ese individuo privilegiado y se ciñen sobre el panorama hechos eminentemente conceptuales, como la simple elección del artista de un objeto cualquiera y vulgar para su categorización de obra de arte, la masa aparta su interés y se vuelve irremediablemente nostálgica con obras pasadas. Es ajena al compromiso del arte con el arte, no comprende su necesidad de superación continua $\mathrm{y}$, por tanto, la perpetua búsqueda y abandono de sistemas de codificación, representación o incluso presentación a medida que cambia la inquietud desde la que nace la obra y, a su vez, a medida que se amplían las posibilidades de "materializar" esas ideas, emociones o propuestas. El espectador obvia el ideal humanizador del arte: la generación de cultura, porque minimiza la cuestión al limitarla a experiencias pasadas, a la cultura que conoce.

En este punto, es fundamental reflexionar sobre las diferentes connotaciones que el concepto de cultura adquiere para el público ajeno al arte y a sus necesidades, y para la creación artística y las demandas que la generan. El primer grupo asocia la cultura a la experiencia vivida y la encierra en un halo costumbrista y popular. Paralelamente, mantiene en alta consideración al concepto traspasando los límites anteriores, en sus referencias a períodos pasados cerrados por la historia y que la actualidad aglutina bajo el manto de lo clásico. El arte, sin embargo, asume la cultura de forma natural, es inherente a su propia definición y, entre otros determinantes que conforman su existencia, destaca el valor de la progresión.

Esta divergencia se hace más visible si centramos la atención en la postura adoptada por cada una de las partes en relación al complejo proceso de culturalización: la del público, por tanto, mira al pasado, limita el valor de progreso a áreas desvinculadas del arte, legitimizándolas en detrimento de este. La mirada del arte, en cambio, solo se dirige al futuro, es su deber. Por ello, en la mirada retrospectiva del arte actual, el artista recopila, recoge y recicla elementos, ideas o concepciones del pasado, pero lo hace guiado por un propósito muy diferente: dar respuesta a inquietudes actuales. En la revisión que propone, algunos ven signos de agotamiento, pero sería menos apocalíptico reconocer en el eclecticismo formal o conceptual uno de los condicionantes fundamentales del contexto actual, de la cultura visual.

En respuesta a la pregunta planteada respecto a la exigencia del público a la obra y en relación a los argumentos expuestos, nos encontramos ante una verdad ineludible: el espectador hace tiempo que dejó de interesarse por el arte porque no encuentra en él ningún resquicio de eso que piensa que le es inherente (de esa manera se ha conformado sus educación perceptiva): el esfuerzo, que sí era visible antes de la progresión cualitativa de la modernidad. 
La consideración de ese esfuerzo, además, no se realiza en base al trabajo intelectual, sino que se refiere a un esfuerzo tangible, visible, en el que sea fácil detectar la habilidad manual "innata" al artista. María Acaso (2009) propone, a través de la educación artística, una revisión de estos esquemas aludiendo a la necesaria relación del arte "con el conocimiento, con el intelecto, con los procesos mentales y no solo con los manuales". Sin embargo el espectador, desconocedor de esta ampliación, continúa recurriendo a la única alternativa que conoce, aquella basada en los preceptos miméticos, narrativos y exclusivamente representativos. Desconfía de urinarios, de estructuras primarias, de apropiaciones, de abstracciones, de performances...

Aún superpone a realizaciones imposibles de categorizar por la propia contemporaneidad, patrones obsoletos incluso para la tradición más arraigada. Antepone a las obras que nacen bajo el flujo de su propia realidad el filtro que supone la mirada retrospectiva. De esta forma no encuentra nexos que amplíen sus estructuras cognitivas ni hay lugar para el encuentro. No se acerca a la obra libre de prejuicios, sino que acarrea toda una serie de significaciones ajenas a las expresiones artísticas contemporáneas, ajenas al Arte, tan incongruentes como el concepto de "lo acabado".

De cualquier modo, tras los hechos acontecidos: después de haber traspasado el arte el límite del objeto, de presenciar el reinado del concepto y otras conquistas, resulta al menos ilusorio mantener en vigor paradigmas que están fuera de los parámetros del arte actual si es que hay unos límites definidos. Tal como afirma Danto (1999), ni siquiera la fórmula de lo moderno, aquella que se suponía "podría servir al arte futuro tan adecuadamente como el paradigma de la mímesis había servido al arte del pasado" es ya un recurso válido. No podemos olvidar que lo novedoso y también, lo caduco, sobrevuelan acechantes.

\section{3. ¿Qué le exige el arte al público?}

Predisposición, una oportunidad.

Solo desde este precepto es posible la experiencia artística, aquella que permite el encuentro íntimo entre: el observador, con una experimentada intuición perceptiva a sus espaldas que actúa como punto de partida, y la "microrrealidad" propuesta por el artista. Esta acción formada por la coincidencia de dos formas reflexivas completamente ajenas tiene una capacidad única de generar concepciones intelectuales muy complejas que, a su vez, hacen posible la cultura. Este proceso emergente se desarrolla, además, sobre unas premisas de aprendizaje muy singulares que permiten calificar esa experiencia única más allá de lo significativo: como una experiencia reveladora. En algunos de los condicionantes específicos que intervienen y que justifican esa dimensión significativa media el descubrimiento, el factor de lo inesperado, pero además, en un análisis global, es importante destacar la intervención de principios subjetivos libres de convencionalismos y de mediaciones estereotipadas. La experiencia artística se adapta al ritmo del individuo-espectador, a sus necesidades, y evoluciona conforme a la modificación cognitiva íntima y única de este. 


\subsection{El contexto del arte}

La relación que el artista mantiene con la obra ha cambiado del mismo modo que ha sido alterado nuestro concepto de realidad, nuestra forma de percibirla y nuestra manera de pensar en ella. Respectivamente: simultaneidad, comunicación o globalidad son algunos de los calificativos que definen a estas nuevas experiencias, a la nueva realidad.

Nuestra concepción del entorno se ha visto modificada de la misma manera en que el concepto de contexto concreto se disipa de forma progresiva e inexorable día a día. Los ciclos de tiempo han pasado de periodos lineales más o menos apacibles, a estallidos o fragmentos cortos que nos hacen permanecer alerta, con la impresión de que cualquier cosa puede suceder y en cualquier momento. Esta sensación es fruto de la ampliación sin límites de la posibilidad comunicativa, del acceso a la información y de la naturaleza de esa comunicación, eminentemente visual.

Si en el análisis que realizamos sobre la relación entre obra de arte (producto de su tiempo) y espectador consideramos, al menos, alguno de estos factores determinantes, comprobaremos el despropósito de anquilosar al arte entre formas de creación acordes con sistemas culturales pasados. No tiene sentido mantener en vigor recursos formales o conceptuales de etapas artísticas anteriores si no es para realizar una revisión efectiva de estos, con lo que modifican su estructura esencial.

Es necesario evidenciar que la obra de arte, en su labor de manifestación, no tiene por qué limitar el medio únicamente a la riqueza en contenido formal-narrativo tal como el espectador espera. Hoy en día, gracias a la ampliación del arte conseguida en el siglo XX, el artista utiliza los medios más insospechados y, en ocasiones, la desconcertante conjunción de varios. Sin embargo el público, en lugar de esperar encontrar en la obra algo nuevo y sorprendente, se obceca en hallar lo conocido. No se preocupa por encontrar en el arte inquietudes nuevas o respuestas diferentes capaces de enriquecer su propia experiencia y, de hecho, solo tolera las formas propiamente artísticas en la medida en que no cuestionan su percepción de la realidad que conoce, cosa muy diferente del verdadero goce artístico.

¿Por qué al arte, la alternativa por excelencia que nos permite comprender el mundo que nos rodea, se le exige la permanencia y subyugación a esos recursos, denostando su capacidad innovadora? Porque se desestima su potencial. El espectador no es capaz de detectar y por tanto de asumir el nuevo poder que este le otorga. No intenta superar la mirada del artista añadiendo nuevas conexiones basadas en la experiencia personal y unívoca.

En el carácter elitista que le presupone, no atisba la concesión que hace la obra al mostrarse inconclusa, como un ente sometido al raciocinio, a la experimentación y a la visión heterogénea de espectadores variopintos que establecerán juicios de valor o buscarán respuestas de índole muy diversa frente a ella. El público ni siquiera intuye que ese poder puede ser compartido.

Su educación artística está fundamentada en un proceso unidireccional basado en la interpretación de lo que el artista intenta decir, sin embargo, tal como Freedman (2006) expone, al tratarse de una "forma de producción social" en la que la obra de arte es solo el producto, es esencial la figura del espectador pues solo en la interacción 
de ambos se produce la relación social.

La realidad global impone sus normas y da al individuo la posibilidad de acercarse a alternativas artísticas ajenas a su entorno inmediato. En principio esta baza juega a favor de la humanización pero, del mismo modo, actúa en su contra. Lo que le llega es un producto mediado más allá de la intervención del artista, un producto sujeto a la tiranía del medio o del canal de transmisión. Pero además, esta difusión contra-actúa con las premisas que el propio arte de la contemporaneidad define como esenciales: la participación activa del espectador, aquello que permite la activación de la obra. La bidireccionalidad necesaria entre obra y observador también comienza a deshumanizarse.

De cualquier modo, una de las premisas del arte de hoy se basa en el deseo de trascender el objeto artístico en su concepción tradicional, del mismo modo que el artista traspasó hace ya tiempo el concepto de proceso con la arquetípica acción de Pollock y con la paradigmática acción de Duchamp. Desde el momento en que la realidad impone unas nuevas pautas a considerar, cambia la intención que estimula la creación y, como consecuencia inmediata, la apariencia de la obra de arte se ve alterada.

\section{El artista}

Si extrapolamos este proceso a la estereotipada figura del artista, hallaremos nuevos condicionantes que interfieren en su propia labor y en la apreciación de la obra por el público.

Hasta hace algunas décadas, los artistas solían circunscribirse de algún modo (conceptual, formal o moralmente) a estilos definidos en base también a preceptos, formas de actuar o de entender el arte. En principio, la adhesión se producía en sentido unidireccional respecto a dos opciones: al estilo imperante o predominante, aquél que contaba con la aprobación y el respaldo de las clases dirigentes, o bien a manifestaciones contrarias, aparentemente, a estos estilos. Al poco tiempo, tal contrariedad se transformaba en cambio cualitativo que por su carácter novedoso, por su aportación, tardaba en ser reconocido. A pesar de esto, algunas de las grandes figuras del arte caminaron en solitario.

De ese modo, la circunscripción a algo más o menos definido y más o menos asimilado, daba al espectador pistas sobre el estilo del artista y así, mediante el reconocimiento de sus obras, en la detección de su estilo personal, salvaba la distancia de lo desconocido, lo ajeno. Ese grado de familiaridad formal, en ocasiones, compensaba otro tipo de "pérdidas" tales como la narración o la mímesis en la representación. En la actualidad, el carácter interdisciplinar del arte, su liberación del objeto, su extensión, dificulta este proceso, anulando otro de los resortes que el público utilizaba. La posibilidad de identificación, de reconocimiento, es también más difícil.

En el proceso de creación que se inicia en el mundo inmanente- inmaterial en el que nace la inquietud artística, y que culmina en la manifestación, expresión o materialización de esta a través de determinadas imbricaciones formales ya en la realidad externa, el artista actual, obvia resortes a los que el espectador permanece aferrado, como la aparición de lo narrativo. A diferencia de otros períodos, el análisis 
del paisaje exterior por el artista actual requiere un proceso de retraimiento hacia un nuevo concepto de paisaje interior del que ya no es necesario salir, basta con materializar lo etéreo en lo corpóreo. El problema, la deshumanización, se hace aún mayor cuando incluso lo corpóreo, la materialización del arte, ha sufrido un proceso similar.

Sin embargo, parece que hoy por hoy, no se exige al artista que demuestre en cada una de sus obras sus cualidades técnicas. En teoría, este es uno de los fundamentos esenciales que caracterizan al arte contemporáneo, pero en la práctica, esta afirmación constituye uno de los paradigmas más quiméricos.

\section{Conclusiones. La deshumanización del arte}

El arte de hoy, fruto de continuas mutaciones, híbridos o deconstrucciones, parece ser un arte diferente, un arte que ha traspasado la frontera de lo humano para asumir apariencia divina en la misma medida en que actúa en un espacio aparentemente inaccesible.

Teóricos como Danto (1999) ven en la transgresión de condiciones productivas (eco de una sociedad extremadamente compleja) algo más y proclaman la muerte del arte en la medida en que señalan el nacimiento de algo nuevo, de algo distinto que, por sus características, ha excedido los límites de lo que hasta entonces considerábamos bajo esa denominación.

Muchos son los factores que han propiciado esta situación. Tal como hemos comprobado, algunos de ellos nacen de premisas que arrastra el arte y que en nada contribuyen a su accesibilidad como son: la propia sublimidad que asociamos a la manifestación artística, la falsa concepción de la necesidad de conocimientos previos para la experiencia del arte, o la imperiosa búsqueda de lo narrativo. Otros condicionantes proceden de la propia esfera del arte: el uso de un lenguaje que nace del mundo de la introspección, por lo que sus resortes tienen ya un elevado índice de abstracción; el alto grado de innovación técnica asumida por la creación contemporánea, o la emergencia de un arte territorialmente simultaneado, libre del sometimiento a manifestaciones fuertemente arraigadas a un contexto particular.

No obstante, a pesar de la complejidad de algunos de los preceptos que conforman el arte actual: interdisciplinariedad, globalidad o heterogeneidad, la creación artística de los últimos años propone alternativas sugerentes basadas en canales esencialmente participativos, en encuentros lúdicos o en vivencias multisensoriales que deben ser consideradas. Sin embargo, el espectador permanece aferrado a presupuestos obsoletos, aquellos que siguen conformando sus estructuras referenciales, desechando así el verdadero encuentro con el arte.

La consecuencia de este desencuentro es previsible: en el instante en que el arte queda despojado de la única función que le es propia: la transmisión de una inquietud (sea de la naturaleza que sea), de una idea o de una emoción, del individuo-artista a la colectividad, se produce la deshumanización. 


\section{Referencias}

Acaso, M. (2009). La educación artística no son manualidades. Madrid: Catarata.

Aznar-Almazán, S. (2000). El arte de acción. Hondarribia (Guipúzcoa), Nerea.

Beardsley, M., C. Hosper, J. (1997). Estética, Historia y fundamentos. Madrid, Cátedra.

Brea, J. L. (2002). La era postmedia. Acción comunicativa, prácticas (post)artísticas $y$ dispositivos neomediales. Salamanca, Centro de Arte de Salamanca.

Chavarría, J. (2002). Artistas de lo Inmaterial. Hondarribia (Guipúzcoa), Nerea.

Chipp, H. B. (1995). Teorías del arte contemporáneo. Fuentes artísticas y opiniones críticas. Madrid, Akal.

Crow, T. (2001). El esplendor de los sesenta. Arte americano y europeo en la era de la rebeldía 1955-1969. Madrid, Akal / Arte en contexto.

Crow, T. (2002). El arte moderno en la cultura de lo cotidiano. Madrid, Akal.

Danto, A. (1999). Después del fin del arte. El arte contemporáneo y el linde de la historia. Barcelona, Paidós. (Ed. Orig. 1997).

Dewey, J. (2008). El arte como experiencia. Barcelona, Paidós Ibérica.

Efland, A. D., Freedman, K. Y Stuhr, P. (2003). La educación en el arte posmoderno. Barcelona, Paidós.

Foster, H. (2001). El retorno de lo real. La vanguardia a finales de siglo. Madrid, Akal/Arte Contemporáneo.

Foster, H., Krauss,B., Bois, Y., Buchloh, B. (2006). Arte desde 1900. Madrid, Akal.

Freedman, K. (2006). Enseñar la cultura visual. Currículum, estética y vida social del arte. Barcelona, Octaedro.

Harvey, D. (1998). La condición de la posmodernidad: investigación sobre los orígenes del cambio cultural. Buenos Aires, Amorrortu.

Hauser, A. (1975). Fundamentos de la sociología del arte. Madrid, Guadarrama.

Kandinsky, W. (1996). De lo espiritual en el arte. Barcelona, Paidós.

Lippard, L. R. (2004). Seis años: la desmaterialización del objeto artístico de 1966 a 1972. Madrid, Akal.

Lyotard, J. F. (2000). La condición postmoderna. Informe sobre el saber. Madrid, Cátedra.

Marchán, S. (2001). Del arte objetual al arte de concepto. Epílogo sobre la sensibilidad "postmoderna". Madrid, Akal. (Ed. Orig. 1972).

Marina, J.A. (6/02/2000). El arte ingenioso. El Cultural. 3.

Ortega y Gasset, J. (1987). La deshumanización del arte y otros ensayos de estética. Madrid, Espasa Calpe.

Picó, J. (1998). Modernidad y Posmodernidad. Madrid, Alianza.

Ramírez, J. A. Y Carrillo, J. (eds.) (2004). Tendencias del arte, arte de tendencias a principios del siglo XXI. Madrid, Cátedra.

Read, H. (1999). Educación por el arte. Barcelona, Paidós.

Read, H. (2000). Arte y Alienación. Valencia, Ahimsa.

Wallis, B. (Ed.). (2001). Arte Después de la Modernidad. Nuevos planteamientos en torno a la representación. Madrid: Akal. 